\title{
MULTIPLICAÇÃO IN VITRO DOS PORTA-ENXERTOS DE Prunus sp. 'BARRIER' E 'CADAMAN'1
}

\author{
MARCELO COUTO², ROBERTO PEDROSO DE OLIVEIRA, GERSON RENAN DE LUCES FORTES ${ }^{4}$
}

\begin{abstract}
RESUMO - Este trabalho foi realizado com o objetivo de estabelecer a melhor concentração de sais do meio MS e da citocinina BAP para a multiplicação dos porta-enxertos de Prunus sp. 'Barrier' e 'Cadaman'. Segmentos nodais foram introduzidos em tubos de ensaio contendo $10 \mathrm{~mL}$ de meio de cultura com variações na concentração de sais (MS; 1/2MS; e 2/3MS) combinadas com cinco concentrações de BAP ( 0 ; 1,5; 2,5; 3,5 e 4,5 $\mu \mathrm{M}$ ). Utilizou-se um fatorial $2 \times 3 \times 5$, distribuído em blocos casualizados, compostos por quatro repetições contendo cinco tubos de ensaio cada uma, sendo inoculado um segmento nodal por tubo. As avaliações foram realizadas após cinco semanas de cultivo em ambiente com intensidade luminosa de 20 $\mu \mathrm{E} \mathrm{m}^{-2} \mathrm{~s}^{-1}$, fotoperíodo de 16 horas e temperatura de $24 \pm 4^{\circ} \mathrm{C}$. Verificou-se maior número médio de gemas e de brotações para a cultivar Barrier. À medida que se reduziu a concentração de sais do meio de cultura, obteve-se maior número de brotações, porém com menor tamanho. As regressões polinomiais das variáveis número de gemas, brotações por explante e comprimento das brotações apresentaram um ajustamento quadrático para níveis de BAP, atingindo os pontos de máximo 31,2 gemas/explante; 4,6 brotações por explante, e 8,1 mm de comprimento nas concentrações 3,3; 3,1, e 3,1 $\mu \mathrm{M}$ de BAP, respectivamente.
\end{abstract}

Termos para indexação: 6-benzilaminopurina, cultura de tecidos, micropropagação, pessegueiro.

\section{in VITRO MULTIPLICATION OF 'BARRIER' AND 'CADAMAN' Prunus sp. ROOTSTOCKS}

\begin{abstract}
The objective of this work was to establish the best salt and BAP concentration in MS medium for multiplication of 'Barrier' and 'Cadaman' Prunus sp. rootstocks. Nodal segments were introduced in test tubes with $10 \mathrm{~mL}$ of MS medium supplemented with different salt concentrations (MS; $1 / 2 \mathrm{MS}$; and 2/3MS) arranged with five BAP concentrations $(0 ; 1.5 ; 2.5 ; 3.5$; and $4.5 \mu \mathrm{M})$. It was applied a factorial $2 \times 3 \times 5$, in a complete randomized block design with four replications composed by five test tubes each one. It was inoculated one nodal segment for each test tub. The evaluations was carried out after five weeks in room culture with light intensity of $20 \mu \mathrm{E} \mathrm{m} \mathrm{m}^{-2}$, photoperiod of 16 hours and temperature of $24 \pm$ $4^{\circ} \mathrm{C}$. It was verified that cultivar 'Barrier' showed the higher average number of buds and shoots. The reduction of the salt concentration of the culture medium increased the number of shoots, although with smaller size. The polynomial regressions of the variables number of buds, shoots per explant, and length of shoots presented a quadratic behavior to BAP levels, presenting the maximum points 31.2 buds per explant; 4.6 shoots per explant; and $8.1 \mathrm{~mm}$ of length at BAP concentrations of $3.3 ; 3.1$; e $3.1 \mu \mathrm{M}$, respectively.
\end{abstract}

Index terms: 6-benzilaminopurine, tissue culture, micropropagation, peach tree

\section{INTRODUÇÃO}

No Brasil, anualmente, são produzidas 150 mil toneladas de pêssego em uma área de 22 mil ha, sendo o Estado do Rio Grande do Sul responsável por $60 \%$ da produção (Agrianual, 2003). A produção destinase ao mercado de frutas frescas e à industrialização, sendo freqüente a realização de importações para atender à demanda interna (Chalfun \& Hoffmann, 1997). Um dos principais fatores limitantes à cultura no País refere-se à falta de mudas de alta qualidade genética, fitossanitária e fitotécnica.

A propagação do pessegueiro vem sendo realizada por meio de enxertia, utilizando porta-enxertos produzidos principalmente a partir de sementes, o que acarreta constante variabilidade genética do pomar (Fachinello et al., 1994). As principais cultivares utilizadas no Sul do Brasil são o 'Capdeboscq' e o 'Aldrighi', os quais são altamente suscetíveis ao nematóide Meloidogyne incognita (Mauch, 1991). Há vários anos, pesquisadores da Embrapa Clima Temperado e da Universidade Federal de Pelotas vêm dedicando-se à introdução, melhoramento genético, propagação e avaliação de diferentes portaenxertos para Prunus. Dentre as cultivares introduzidas, destacam-se a 'Barrier' e a 'Cadaman', ambas híbridas provenientes do cruzamento Prunus persica x $P$. davidiana. A cv. Barrier apresenta tolerância a nematóides do gênero Meloidogyne e à asfixia das raízes (Finardi, 1998), enquanto a cv. Cadaman apresenta sistema radicular profundo, adaptando-se a diferentes tipos de solo e condições de umidade (Felipe, 1994).

A multiplicação de porta-enxertos de Prunus por meio de estaquia raramente tem sido empregada em função da baixa capacidade de enraizamento da maioria das cultivares de importância econômica (Chalfun \& Hoffmann, 1997).
A produção in vitro de porta-enxertos vem sendo realizada de forma comercial em vários países, principalmente na Itália (Loreti \& Massai, 1995), não sendo utilizada no Brasil em função da inexistência de um método economicamente viável. A micropropagação apresenta as vantagens de possibilitar a produção massal de mudas livres de patógenos e com uniformidade genética em pequeno espaço físico e curto período de tempo, de forma a atender às exigências das entidades fiscalizadoras e às necessidades dos produtores de mudas de qualidade (Oliveira et al., 2001).

A micropropagação de espécies de Prunus tem apresentado problemas de oxidação, contaminação por bactérias provavelmente endofíticas, dificuldade de enraizamento e, principalmente, baixa taxa de multiplicação dos explantes, havendo a necessidade de maiores estudos (Chalfun \& Hoffmann, 1997). Além disso, existe uma resposta diferencial em relação aos genótipos (Parfitt \& Almehdi, 1986).

Este trabalho teve por objetivo estabelecer a melhor concentração de sais do meio MS (Murashige \& Skoog, 1962) e da citocinina BAP (6-benzilaminopurina) para a multiplicação in vitro dos porta-enxertos de Prunus sp. 'Barrier' e 'Cadaman'.

\section{MATERIALEMÉTODOS}

O material vegetal utilizado foi composto de segmentos nodais (5 a $10 \mathrm{~mm}$ ) de plântulas dos porta-enxertos de Prunus sp. 'Barrier' e 'Cadaman' cultivadas in vitro, por cinco subcultivos de 30 dias, em meio 1/2MS suplementado com $0,3 \mathrm{mg} \mathrm{L}^{-1}$ de BAP.

O meio de cultura básico usado no experimento foi o MS suplementado com $10 \mathrm{mg} \mathrm{L}^{-1}$ de ácido ascórbico; $0,5 \mathrm{mg} \mathrm{L}^{-1}$ de ácido cítrico; $1 \mathrm{mg} \mathrm{L}^{-1}$ de ácido nicotínico; $2 \mathrm{mg} \mathrm{L}^{-1}$ de glicina; 0,5 $\mathrm{mg} \mathrm{L}^{-1} \mathrm{de}$

\footnotetext{
${ }^{1}$ (Trabalho 147/2003). Recebido: 08/10/2003. Aceito para publicação: 16/01/2004.

${ }^{2}$ Bolsista da CAPES. Faculdade de Agronomia Eliseu Maciel - FAEM/UFPel, CP. 354, 96010-9000, Pelotas-RS. E-mail: couto@ cpact.embrapa.br

${ }^{3}$ Embrapa Clima Temperado, CP. 403, 96001-970, Pelotas-RS - Bolsista CNPq. E-mail: rpedroso@cpact.embrapa.br

${ }^{4}$ Embrapa Recursos Genéticos e Biotecnologia, CP. 02372, 70849-960, Brasília-DF - Bolsista CNPq. E-mail: gerson@ @enargen.embrapa.br
} 
TABELA 1 - Resumo da análise da variação e testes de significância para as variáveis número de gemas, número de brotações e comprimento das brotações (mm).

\begin{tabular}{lcccc}
\hline & GL & & Quadrados médios & \\
\cline { 3 - 5 } Causas da Variação & & Número de gemas & Número de brotações & Comprimento das brotações \\
\hline Blocos & 3 & - & - & - \\
Porta-enxerto (A) & 1 & $7,5^{* *}$ & $1,0 *$ & $0,0 \mathrm{~ns}$ \\
Meio de cultura (B) & 2 & $1,9 \mathrm{~ns}$ & $1,6^{* *}$ & $0,9 * *$ \\
BAP (C) & 4 & $37,3 * *$ & $4,6 * *$ & $0,6^{* *}$ \\
A x B & 2 & $0,9 \mathrm{~ns}$ & $0,2 \mathrm{~ns}$ & $0,1 \mathrm{~ns}$ \\
A x C & 4 & $0,6 \mathrm{~ns}$ & $0,3 \mathrm{~ns}$ & $0,2 \mathrm{~ns}$ \\
B x C & 8 & $1,2 \mathrm{~ns}$ & $0,3 \mathrm{~ns}$ & $0,1 \mathrm{~ns}$ \\
A x B x C & 8 & $1,3 \mathrm{~ns}$ & $0,2 \mathrm{~ns}$ & $0,1 \mathrm{~ns}$ \\
Resíduo & 87 & 0,8 & 0,2 & 0,1 \\
\hline CV $(\%)$ & & 18,9 & 21,2 & 44,7
\end{tabular}

ns - não significativo ao nível de $5 \%$ de probabilidade, pelo teste $\mathrm{F}$.

* e** significativo pelo teste $\mathrm{F}$, aos níveis de 5 e $1 \%$ de probabilidade, respectivamente.

piridoxina; $0,5 \mathrm{mg} \mathrm{L}^{-1}$ de tiamina; $100 \mathrm{mg} \mathrm{L}^{-1}$ de mio-inositol; $30 \mathrm{~g} \mathrm{~L}^{-1} \mathrm{de}$ sacarose, e $6 \mathrm{~g} \mathrm{~L}^{-1}$ de ágar, com $\mathrm{pH}$ ajustado para 5,8 antes da autoclavagem a $121^{\circ} \mathrm{C}$, por 15 minutos.

A multiplicação in vitro dos explantes dos dois porta-enxertos ('Barrier' e 'Cadaman') foi estudada sob variações na concentração de sais (MS; $1 / 2 \mathrm{MS}$; e 2/3MS) combinadas com cinco concentrações de $\operatorname{BAP}(0 ; 1,5 ; 2,5 ; 3,5$ e $4,5 \mu \mathrm{M})$. O delineamento experimental foi um fatorial $2 \times 3 \times 5$, distribuído em blocos casualizados, compostos por quatro repetições, contendo cinco tubos de ensaio $(20 \times 150 \mathrm{~mm})$ cada uma, sendo inoculado um segmento nodal por tubo, contendo $10 \mathrm{~mL}$ de meio de cultura. A cultura dos explantes foi realizada em ambiente com intensidade luminosa de $20 \mu \mathrm{E} \mathrm{m}^{-2} \mathrm{~s}^{-1}$, fotoperíodo de 16 horas e temperatura de $24 \pm 4^{\circ} \mathrm{C}$. Após cinco semanas, foram avaliadas as variáveis número de gemas, número e comprimento das brotações ( $\mathrm{mm})$. A análise estatística dos dados para os fatores porta-enxerto e variações do meio MS foi realizada por meio de comparação de médias, pelo teste de Duncan, e para os níveis de BAP, por meio de regressão polinomial, utilizando o programa SANEST - Sistema de Análise Estatística para Microcomputadores (Zonta \& Machado, 1984). O nível mínimo de significância adotado foi de $5 \%$, sendo os dados das variáveis número de gemas e de brotações transformados para $(x+1)^{1 / 2}$ e $(x+0,5)^{1 / 2}$, respectivamente.

\section{RESULTADOS E DISCUSSÃO}

Os porta-enxertos 'Barrier' e 'Cadaman' apresentaram diferenças significativas quanto ao potencial de multiplicação in vitro, o que foi quantificado pela avaliação do número de gemas e de brotações produzidas por explante (Tabela 1). A cv. Barrier apresentou o melhor desempenho, com média de 3,6 brotações por explante durante o subcultivo de cinco semanas avaliado (Tabela 2). Desenvolvimento in vitro diferencial entre cultivares já havia sido relatado entre outros portaenxertos de Prunus por Hammerschlag (1982), Parfitt \& Almehdi (1986) e Zimmerman (1988). Ao comparar-se com outras espécies perenes, a taxa de multiplicação de 2,9 obtida inclusive para a cv. Cadaman também pode ser considerada satisfatória.

Independentemente da cultivar e da quantidade de citocinina adicionada ao meio de cultura, observou-se efeito da concentração de

TABELA 2 - Número médio de gemas e de brotações por explante dos porta-enxertos de Prunus sp. 'Barrier' e 'Cadaman' e resultados do teste de comparação de médias.

\begin{tabular}{lcc}
\hline $\begin{array}{l}\text { Porta- } \\
\text { enxertos }\end{array}$ & $\begin{array}{c}\text { Número médio } \\
\text { de gemas/explante }\end{array}$ & $\begin{array}{c}\text { Número médio } \\
\text { de brotações/explante }\end{array}$ \\
\hline 'Barrier' & $24,2 \mathrm{a}$ & $3,6 \mathrm{a}$ \\
'Cadaman' & $19,4 \mathrm{~b}$ & $2,9 \mathrm{~b}$ \\
\hline
\end{tabular}

Médias seguidas de letras diferentes nas colunas diferem entre si, pelo teste de Duncan $(p<0,05)$.
TABELA 3 - Número médio de brotações por explante e comprimento médio das brotações (mm) dos porta-enxertos de Prunus sp. 'Barrier' e 'Cadaman', em diferentes concentrações dos sais do meio MS e resultados dos testes de comparação de médias.

\begin{tabular}{ccc}
\hline $\begin{array}{c}\text { Concentrações } \\
\text { do meio MS }\end{array}$ & $\begin{array}{c}\text { Número médio } \\
\text { de brotações/explante }\end{array}$ & $\begin{array}{c}\text { Comprimento médio } \\
\text { das brotações }(\mathrm{mm})\end{array}$ \\
\hline 1 & $2,6 \mathrm{~b}$ & $8,7 \mathrm{a}$ \\
$2 / 3$ & $3,0 \mathrm{~b}$ & $7,3 \mathrm{a}$ \\
$1 / 2$ & $4,1 \mathrm{a}$ & $5,7 \mathrm{~b}$ \\
\hline
\end{tabular}

Médias seguidas de letras diferentes na coluna diferem entre si, pelo teste de Duncan $(p<0,05)$.

sais do meio MS na multiplicação dos explantes (Tabela 1). O maior número médio de brotações por explante $(4,1)$ foi obtido no meio $1 / 2 \mathrm{MS}$, enquanto o maior comprimento médio de brotações $(8,7 \mathrm{~mm})$ no meio MS com concentração original de sais. Segundo Parfitt \& Almehdi (1986), taxas de multiplicação próximas a 5,0 são bastante satisfatórias para espécies de Prunus. Conforme se pode observar na Tabela 3, um maior desenvolvimento dos explantes quanto ao número de brotos implica menor comprimento das brotações e vice-versa. No presente trabalho, demonstrou-se que a regulação dessa resposta pode ser realizada por variações na concentração de sais do meio MS. Isto é importante para controlar o processo de multiplicação in vitro dos explantes ao longo dos subcultivos durante a micropropagação dos porta-enxertos 'Barrier' e 'Cadaman'.

As regressões polinomiais das variáveis número de gemas, brotações por explante e comprimento das brotações apresentaram um ajustamento quadrático para níveis de BAP, atingindo os pontos de máximo 31,2 gemas por explante; 4,6 brotações por explante, e $8,1 \mathrm{~mm}$ de comprimento nas concentrações 3,3; 3,1 e 3,1 $\mu \mathrm{M}$ de BAP, respectivamente (Figuras 1, 2 e 3 ). Desta forma, o uso de 3,1 $\mu \mathrm{M}$ de BAP pode ser recomendado para a multiplicação in vitro de ambos os portaenxertos de Prunus estudados. Embora esta mesma concentração tenha sido também definida como a mais indicada para a micropropagação dos porta-enxertos 'Marianna', 'Mr.S 2/5' e 'G x N ${ }_{22}$ ' (Silveira et al., 2001), 'Hansen 2168' e 'Hansen 536' (Martinelli, 1985), não podem ser feitas generalizações. Parfitt \& Almehdi (1986) obtiveram taxas diferentes de multiplicação ao trabalharem com 56 cultivares de pessegueiro.

Mesmo no meio de cultura sem adição de BAP, houve multiplicação dos explantes de 'Barrier' e de 'Cadaman' (Figura 2), o que pode ser atribuído a um efeito residual do meio utilizado nos cinco subcultivos anteriores. O uso de 4,5 $\mu \mathrm{M}$ de BAP proporcionou desenvolvimento de um menor número de gemas e de brotações em ambas as cultivares em relação a 3,5 $\mu \mathrm{M}$ de BAP, sugerindo ser uma concentração excessiva desse regulador de crescimento. Chiariotti \& Antonelli (1988) já haviam demonstrado redução na taxa de multiplicação de explantes de pessegueiro, porém somente ao utilizar-se concentrações superiores a $20 \mu \mathrm{M}$ de BAP. 


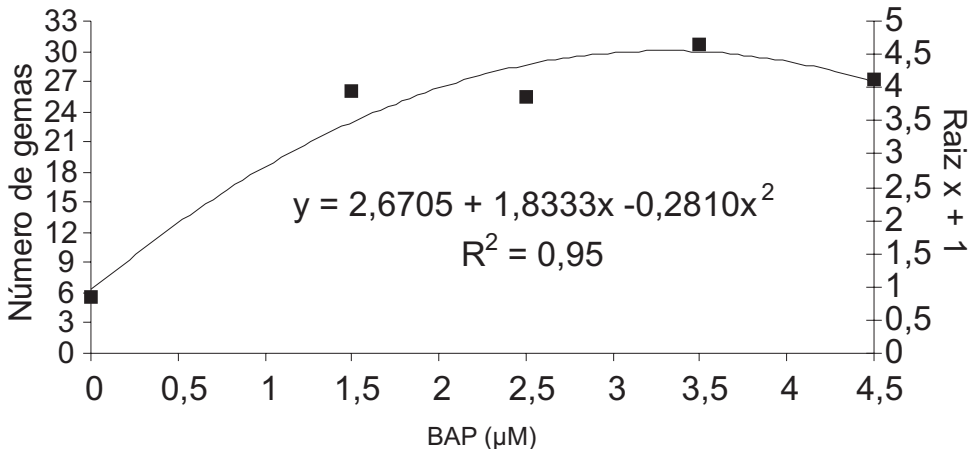

FIGURA 1 - Número médio de gemas por explante de cultivares de portaenxerto de Prunus sp. em função de concentrações de BAP.

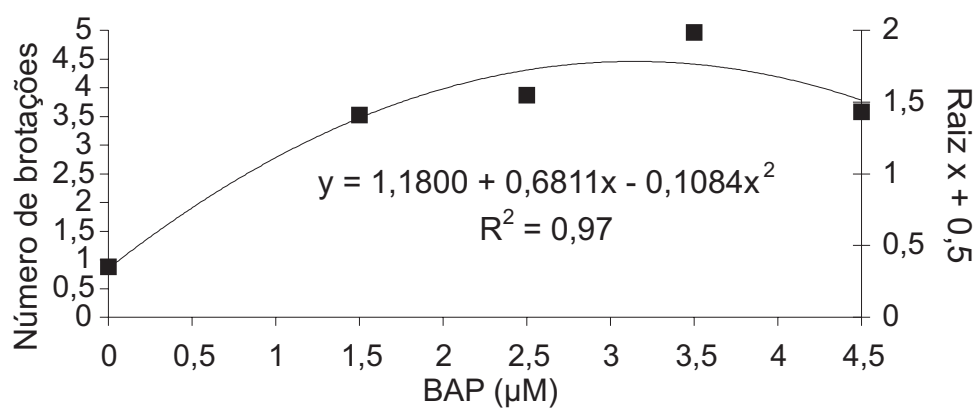

FIGURA 2 - Número médio de brotações por explante de cultivares de porta-enxerto de Prunus sp. em função de concentrações de BAP.

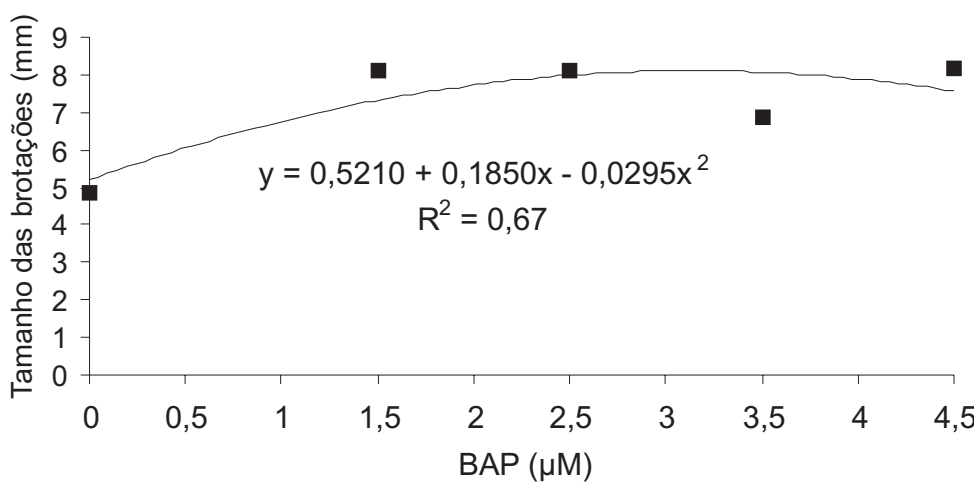

FIGURA 3 - Comprimento médio das brotações ( $\mathrm{mm}$ ) de cultivares de porta-enxerto de Prunus sp. em função de concentrações de BAP.

Durante o experimento, não foram observadas plântulas com sintomas de vitrificação, oxidação, encarquilhamento ou clorose das folhas, sugerindo desenvolvimento normal dos explantes.

\section{CONCLUSÕES}

1) A cv. Barrier apresenta maior potencial genético para multiplicação in vitro em relação à 'Cadaman'.

2) A concentração de sais do meio de cultura pode ser utilizada para controlar o desenvolvimento e a multiplicação de explantes de porta-enxertos de Prunus durante a micropropagação.

3) A suplementação do meio de cultura MS com $3,1 \mu \mathrm{M}$ de BAP é recomendada para a multiplicação in vitro dos porta-enxertos de Prunus 'Barrier' e 'Cadaman'.

\section{REFERÊNCIASBIBLIOGRÁFICAS}

AGRIANUAL: Anuário da Agricultura Brasileira. São Paulo. FNP Consultoria \& AgroInformativos, 2003. 544p.

CHALFUN, N.N.J.; HOFFMANN, A. Propagação do pessegueiro e da ameixeira. Informe Agropecuário, Belo Horizonte, v.18, n.189, p.2329, 1997.

CHIARIOTTI, A.; ANTONELLI, M. The effect of 6-BAP and adenine sulphate on peach shoot proliferation. Acta Horticulturae, Wageningen, v.227, p.418-420, 1988.

FACHINELLO, J.C.; HOFFMANN, A.; NACHTIGAL, J.C.; KERSTEN, E.; FORTES, G.R.L. Propagação de plantas frutíferas de clima temperado. Pelotas: UFPEL, 1994. 179p.

FELIPE, A.J. Portainjertos para duraznero y ciruelo. Rio Negro: INTA, 1994. p.1-50.

FINARDI, N.L. Método de propagação e descrição de porta-enxertos. In: MEDEIROS, C.A.B.; RASEIRA, M.C. A cultura do pessegueiro. Brasília: Embrapa-SPI, 1998. p.100-129.

HAMMERSCHLAG, F. Factors affecting establishment and growth of peach shoots in vitro. HortScience, Alexandria, v.17, p.85-86, 1982.

LORETI, F.; MASSAI, R. Portinnesti fruttiferi: Pesco. L'informatore Agrario, n.32, p.37-42, 1995.

MARTINELLI, A. Factors affecting in vitro propagation of the peachalmond hybrids 'Hansen 2168' and 'Hansen 536'. Acta Horticulturae, The Hague, n.173, p.237-244, 1985.

MAUCH, C.H. Comportamento de pessegueiros (Prunus persica $\mathbf{L}$. Batsch) e ameixeira (Prunus cerasifera Ehre) em relação a Meloidogyne incognita, 1991. 64f. Dissertação (Mestrado em Produção Vegetal) - Escola de Agronomia 'Eliseu Maciel', Universidade Federal de Pelotas, Pelotas, 1998

MURASHIGE, T.; SKOOG, F. A revised medium for rapid growth and bioassays with tobacco tissue cultures. Physiology Plantarum, Copenhagen, v.15, p.473-497, 1962.

OLIVEIRA, R.P.; SILVEIRA, D.G.; SILVA, S.O. Concentração de BAPe a eficiência da micropropagação de bananeira tetraplóide (grupo AAAB). Scientia Agricola, Piracicaba, v.58, n.1, p.73-78, 2001.

PARFITT, D.E.; ALMEHDI, A.A. In vitro propagation of peach: II. A medium for in vitro multiplication of 56 peach cultivars. Fruit Varieties Journal, Urbana, v.40, n.2, p.46-47, 1986.

SILVEIRA, C.A.P.; FACHINELLO, J.C.; FORTES, G.R.L.; CITADIN, I.; RODRIGUES, A.C.; QUEZADA, A.C.; SILVA, J.B. Multiplicação in vitro de porta-enxertos do gênero Prunus sob diferentes concentrações de BAP em dois meios de cultura. Revista Brasileira de Fruticultura, Cruz das Almas, v.23, n.3, p.488-492, 2001.

ZIMMERMAN, R.H. Cultivo de tejidos. In: MOORE, J.N.; JANICK, J. (Ed.) Métodos genotécnicos en frutales. México: AGT, 1988. p.167182.

ZONTA, E.P.; MACHADO, A.A. SANEST: Sistema de análise estatística para microcomputadores. Pelotas: Universidade Federal de Pelotas, 1984. $75 \mathrm{p}$ 